\title{
A Alteridade Digital no Processo de Criação em Arquitetura
}

\section{The digital otherness in the architectural design process}

\author{
Vinícius Juliani Pereira \\ Universidade Presbiteriana Mackenzie, Brasil \\ viniciusjulianip@gmail.com \\ Luiz Alberto Fresl Backheuser \\ Universidade Presbiteriana Mackenzie, Brasil \\ luiz.backheuser@mackenzie.com
}

\begin{abstract}
An instrument with high data-processing capacity capable of developing design solutions not previously viewed by the human intellect, should not be seen as a mere design tool. In a world encoded by the virtualization of human relations and the definitive change in the relationship between subject and object, it is the role of the architect to understand what would be his true positioning in a shared design process with a computing device. This article intends to be the beginning of a comprehensive research between theoretical and pratical aspects on the relations established between the agents involved in an algorithmic process of creation in architecture.
\end{abstract}

Keywords: Alteriadade digital; Arquitetura algorítmica; Processos digitais; Criação.

\section{Introdução}

Desde meados dos anos 1960, antes do surgimento das primeiras interfaces comerciais de desenho digital, vem se discutindo qual deve ser o envolvimento do computador dentro da produção arquitetônica. A busca pela informatização de um processo com foco no alto nível produtivo possível de se alcançar, seguido do desenvolvimento da computação gráfica e de softwares de modelagem 3D, fizeram crescer o número de profissionais que defendem a inserção da tecnologia na disciplina (NATIVIDADE, 2010). Entretanto, até pouco tempo, nem mesmo os arquitetos que se auto proclamavam verdadeiros exploradores digitais, tinham claras as reais implicações da computação dentro do processo de projeto.

A inserção de dispositivos computacionais na sociedade civil alterou procedimentos em que anteriormente apenas agente humanos estavam envolvidos. As relações sociais se moldam frente a um mundo conectado em rede (VASSÃO, 2010).

Considerando o processo de criação uma reorganização de elementos conhecidos do que temos como realidade (TERZIDIS, 2006), e que a apreensão dessa realidade se dá por interlocução digital, a arquitetura se apresenta como uma resposta construída às relações sociais, e, portando, deve ser

\footnotetext{
${ }^{1}$ Informatização (computerization): automatização, mecanização e conversão. Envolve a digitalização de entidades ou processos préconcebidos, pré-determinados e bem definidos. Entidades e processos já concebidos na mente do designer são digitalizados e manipulados em um computador (TERZIDIS, 2006);

2 Computação (computation): procedimento de cálculo, determinar algo por métodos matemáticos ou lógicos. Sobre a exploração do indeterminado, vago, não claro e por descobrir. De natureza exploratória, tem a intenção de simular ou ser uma extensão do intelecto humano. Racionalização, raciocínio lógico, algoritmo,
}

o produto de uma criação baseada no contexto em que tais relações acontecem.

\section{Arquitetura Algorítmica}

Como afirma Antoine Picon no prefácio da publicação Algorithm Architecture, de Kostas Terzidis (2006), grande parte dos designers encaram o ambiente digital como um compilado de softwares que possibilitam a produção de formas extravagantes e o controle das mesmas sem interesse algum em entender o processo de obtenção e racionalização da criação.

A maneira dominante de utilização do computador em ambientes de escritórios de arquitetura é a informatização ${ }^{1}$, onde o designer não se apropria do poder de processamento da máquina. A arquitetura algorítmica se apresenta como uma alternativa entre a dicotomia computação ${ }^{2}$-informatização. 0 processo de projeto baseado em scripting ${ }^{3}$ (BURRY, 2011) tem como princípio a elaboração de um conjunto lógico de regras que ultrapassem as limitações impostas por softwares comerciais - a organização de uma ferramenta específica, para um problema específico.

Mark Burry apresenta em seu livro, Scripting Cultures (2011), uma interpretação do desenvolvimento do digital dentro da

dedução, indução, exploração e estimativa. Envolve a resolução de problemas, estruturas mentais, cognição, simulação, "inteligência regrada" (TERZIDIS, 2006);

\footnotetext{
${ }^{3}$ Programação de nível de complexidade baixo. Capacidade que alguns softwares têm em permitir que o usuário adapte, customize ou reconfigure completamente as funções do software em questão (BURRY, 2011), de acordo com suas necessidades projetuais.
} 
arquitetura. Segundo ele, os primeiros estudos relacionados ao uso desse tipo de ferramenta estão em disciplinas técnicas que permeiam a criação em arquitetura. Agora podemos ser testemunhas do uso do digital nas primeiras etapas de concepção, nas etapas que tanto são preenchidas com poéticas autorais, e que no passado chegaram a ser creditadas a entidades divinas (LUCE, 2009).

\section{Algoritmo}

Algoritmos são expressões linguísticas de um problema. Uma descrição sintática com especificidades gramaticais que devem ser seguidas a fim de formular expressões funcionais. A articulação linguística de um algoritmo não serve apenas para descrever as etapas de sua solução, mas para comunicar essas etapas a um outro agente responsável pelo processamento de dados que compõe a expressão: o computador (TERZIDIS, 2006).

Toda linguagem, seja ela natural ou artificial, possui duas componentes de organização (COATES, 2010): um conjunto léxico de símbolos - um alfabeto ou sistema de sinais -; e uma forma de combinar esses símbolos, a sintaxe. O computador é baseado em uma linguagem artificial, assim como qualquer sistema de códigos desenvolvido pelo homem (por exemplo, código morse). Sendo linguagem, ela é passível de ser entendida pelo ser humano depois de treinamento apropriado (COATES, 2010).

A aplicação de script (algoritmo) na arquitetura envolve a combinação de expressões e informações transmitidas em valores numéricos, onde a lógica da matemática consegue estabelecer abstrações e relações espaciais (BURRY, 2011).

A vontade inicial do arquiteto é transmitida ao algoritmo de forma racional, em uma linguagem especifica dentro da programação. Esse desejo é o input que deve permear as soluções apresentadas pelo código. A informação (bit) é o "tijolo" da arquitetura digital. As necessidades programáticas e as características do contexto são transmitidas em forma de dados (data) para a máquina (CHU, 2006).

A inerência matemática e as relações fixas existentes entre sequências numéricas presentes em um algoritmo podem parecer extremamente deterministas e limitadores dentro do processo criativo. Entretanto, os limites impostos por esse novo método estão ligados a fluência humana dentro deste novo ambiente, assim como a inserção de uma nova ferramenta manual dentro de uma marcenaria vai exigir de seus artesões muito tempo para experimentação e erro, até que se atinja seu domínio - e mesmo assim, sempre escaparão do sistema cognitivo humano formas de aplicação daquela ferramenta, considerando os limites combinatórios auto apreendidos pelo cérebro.

4 "By liberating the user of a computer from material concerns associated with labor, skill, or complexity or from emotional factor such as compassion, fatigue, or boredom computers can be utilized as tireless vehicle that allow humans to realize, overcome, and ultimately
"Após aprendermos um código, tendemos a esquecer a sua artificialidade: depois que se aprende o código dos gestos, pode-se esquecer que o anuir com a cabeça significa apenas aquele 'sim' que se serve desse código. Os códigos (e os símbolos que os constituem) tornam-se uma espécie de segunda natureza [...]. " (FLUSSER, 2007, pág. 90).

Karl Chu (2006) cita uma afirmação de Stephen Wolfram em que ele indaga que "[...] todos os processos, sejam produzidos pelo esforço humano, ou ocorridos espontaneamente na natureza, podem ser vistos como computações". Com isso ele inaugura a concepção de que grande parte dos processos encontrados na natureza pode ser rastreado, analisado, e replicado por uma máquina ( $\mathrm{CHU}, 2006)$. Entretanto, podemos afirmar que, questões ligadas a sensibilidade, instinto e intuição, ainda não são passíveis de simulação em código.

Scripting não é um nome interessante de uma ferramenta, é um jeito de pensar um problema. A introdução do processamento digital na concepção de projeto possibilita alargar limitações humanas - uma extensão da mente (TERZIDIS, 2006) -, um sistema artificial com um poder de processamento de informação algumas vezes maior do que o cérebro humano.

"Ao liberar o usuário de um computador de preocupações materiais associadas ao trabalho, habilidade, ou a complexidade de fator emocional, como compaixão, fadiga ou aborrecimento, o computador pode ser utilizado como um instrumento incansável que permite aos humanos perceber, superar e, em última análise, superar os suas próprias limitações físicas e mentais. " (TERZIDIS, 2006, pág. 16, tradução nossa) ${ }^{4}$.

Ao contrário do processo de desenho analógico (mão, lápis e papel), o projeto assistido por computador possui uma estrutura lógica inerente ao seu suporte (NATIVIDADE, 2010).

\section{Experimentações práticas}

O entendimento teórico da concepção compartilhada com a máquina se mostrou como o primeiro resultado dentro da referida pesquisa, seguido de explorações projetuais práticas. Os exercícios em questão apresentam experimentações com scripts de baixo nível de complexidade, desenvolvidos a partir de conhecimentos elementares de programação.

Script 1: A partir de uma dinâmica de script, foi simulado em ambiente virtual digital a ocupação de lotes urbanos no centro de São Paulo (Brasil). Essa simulação é baseada em parâmetros estabelecidos pela legislação de gestão urbana, sendo eles Taxa de Ocupação, Coeficiente de Aproveitamento, recuos e gabarito de altura.

surpass their own physical and mental limitations." (TERZIDIS, 2006, pág. 16). 

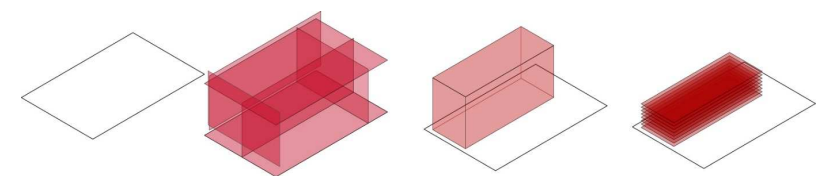

Figura 1: ilustração do funcionamento do script desenvolvido na plataforma de programação gráfica Grasshopper. Da esquerda para a direita: seleção do terreno; definição de planos de contenção do volume considerando dados de legislação de Uso e Ocupação do Solo, e por fim a geração do número total de pavimentos edificáveis possíveis (Imagem do autor).

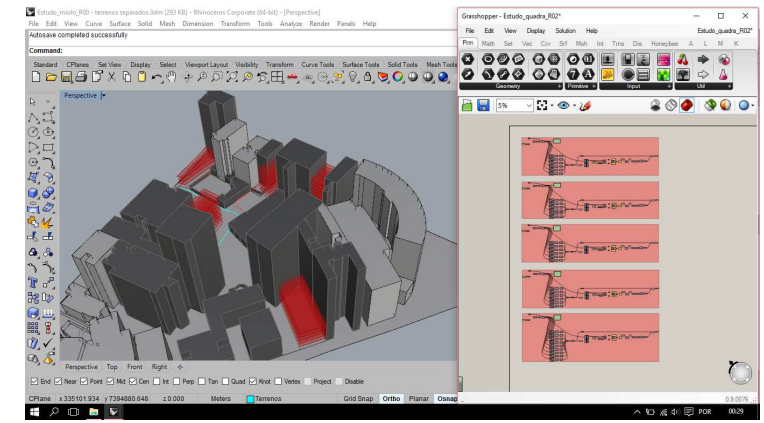

Figura 2: aplicação da dinâmica de Script 1 em um conjunto de lotes de uma mesma quadra urbana localizada na região do Anhagabaú, na cidade de São Paulo-SP (Imagem do autor).

Script 2: Em um segundo momento, aplicando novamente estratégias do Script 1, fora analisado graficamente a projeção de radiação solar nas faces de um volume genérico edificável. Utilizando o plugin Ladybug+Honeybee dentro da interface Grasshopper temos a possibilidade de explorar análises ambientais de forma associativa. Com a utilização de um algoritmo genético - baseado na avaliação de gerações e cruzamento de pares (CALIXTO e CELANI, 2015) - foi possível manipular a curvatura da fachada Leste em que se pretendia uma maximização do ganho de radiação. O prédio ganha um volume com dupla curvatura e um conjunto de varandas na face norte. O estudo apresentado analisa graficamente a projeção de radiação solar nas faces do volume edificável, e os resultados obtidos se tornam inputs para a continuidade das proposições projetuais.

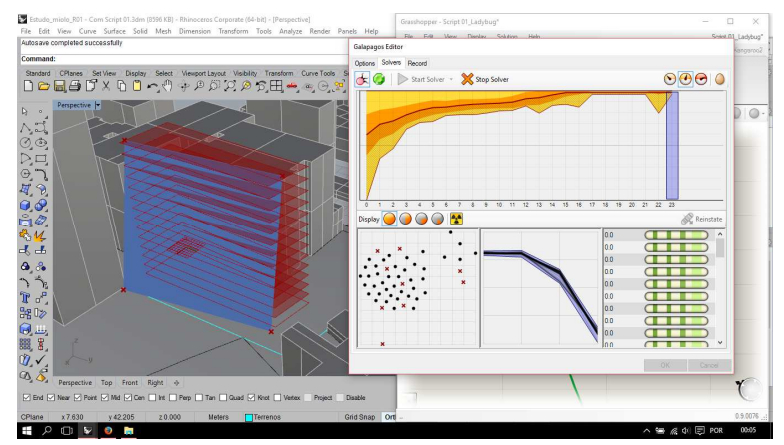

Figura 3: exploração com algoritmo genético a partir do componente Galapagos presente na plataforma Grasshopper. O processamento busca encontrar a melhor insolação para uma fachada selecionada a partir da massa edificável alcançada através da dinâmica aplicada na quadra urbana da Figura 2. (Imagem do autor).

Script 3: O último experimento está relacionado ao desenvolvido de painéis de fechamento vertical de uma préexistência arquitetônica a ser reabilitada dentro do referido exercício projetual. No contexto original, a edificação apresenta alvenaria cerâmica exposta como fechamento de suas fachadas. A proposta aqui é o resgate da estética do padrão de assentamento da cerâmica, agora presente em painéis fabricados a partir da manufatura numérica subtrativa de formas. Os tijolos possuem alturas definidas por estratégia de curvas atratoras dentro da plataforma Grasshopper.
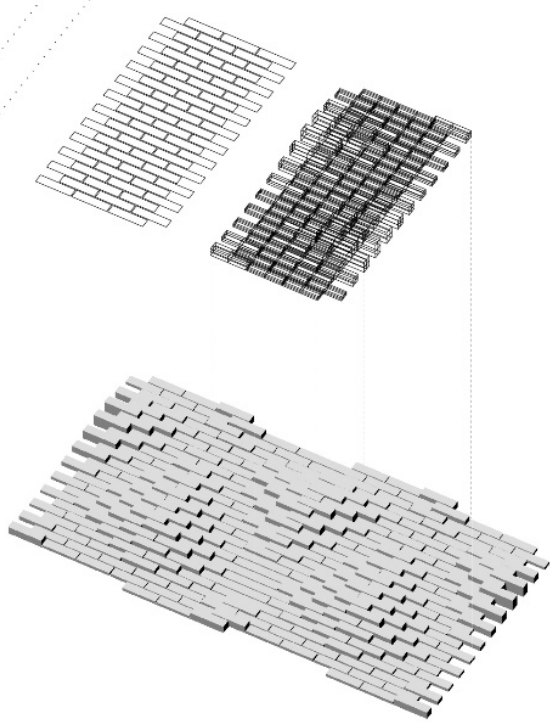

Figura 4: ilustração explicativa das etapas de concepção assistida por computador dos módulos de cerâmica para fachada. Dentro da plataforma Grasshopper, a partir da organização de uma série de pontos, é definida a posição do conjunto de tijolos. Em seguida, a altura de cada tijolo é modificada seguindo a curvatura de uma linha atratora (imagem do autor).

\section{Alteridade digital}

De acordo com o senso comum praticado entre arquitetos e designers, todo o processo criativo envolvendo concepção e intenções são praticados pela mente humana, e o computador seria uma mera ferramenta de organização e apresentação da criação. Em uma análise racional sobre o processo de criação, podemos descreve-lo como uma sucessão de etapas e rigoroso raciocínio (KVAN apud BURRY, 2011), representando nada mais que um pensamento algorítmico.

Em um cenário ideal, estabelecida a sinergia entre homem e máquina, cada uma das partes poderia contribuir com seus pontos fortes dentro do processo de exploração, tentativas e descobertas dentro do design - a sensibilidade humana e a capacidade de processamento digital. A computação não deve ser encarada apenas como uma simulação de etapas analógicas da criação, mas como uma entidade paralela ao 
programador, um parceiro (othernes ${ }^{5}$ ) no processo de criação, um complemento a mente humana6 (TERZIDIS, 2006).

Um segundo olhar (COATES, 2010), mais racional e analítico, livre de intenções ou pré-conceitos ligados à sua própria existência, compara e apresenta soluções de acordo com as informações que lhe são dispostas, um interlocutor que surge quando a compreensão humana é ultrapassada pela questão a ser resolvida.

Existem alguns problemas de projeto cuja complexidade, o nível de incertezas, ambiguidade e grande número de soluções possíveis, requerem uma sinergia entre a mente humana e a computação (TERZIDIS, 2006). Nesse momento é que a prática do scripting se justifica (BURRY, 2011). Ao contrário do que acreditam, e da simples automação de procedimentos (informatização), o uso de algoritmos no processo de projeto pode apresentar implicações que talvez nunca tivessem ocorrido pela mente humana. Características de vida artificial e de inteligência artificial7 podem representar o grau de autonomia (HENNO, 2016) que um sistema computacional, paralelo ao pensamento humano, pode apresentar dentro do processo de criação.

Tratamos aqui de um processo de projeto em que duas entidades externas a si mesmas atuam de forma ativa: o homem e a máquina como "parceiros" de projeto. O grau de liberdade dado para esse sistema computacional irá definir a parcela de interferência humana no projeto. Quanto maior esse grau de liberdade, mais próximos podemos chegar da discussão de coautoria da máquina.

O que torna a lógica do algoritmo tão problemática para alguns arquitetos é que ela desafia o caráter artístico-autoral praticado na arquitetura nos últimos anos, desafiando a intuição (BURRY, 2011). A arquitetura desenvolvida a partir de um algoritmo pode não ter um autor específico - autor aqui entendido como artista, que no fazer da arte, emprega suas crenças e vontades críticas, arte como um registro da experiência do fazer de arte. Presenciamos mudanças na organização de trabalho dentro da disciplina. Algoritmos com maior grau de liberdade podem gerar resultados não imaginados pelo indivíduo que gerou suas primeiras linhas de código. A autonomia é concedida pelo próprio programador ao criar um meta-algoritmo8, abrindo implicações no processo de

\footnotetext{
${ }^{5}$ Alteridade, aquilo que é distinto. Allo: o outro, estrangeiro, que possui sua própria lógica e essa talvez não seja compreendida pelos que estão de fora desse sistema próprio.

${ }^{6}$ Computador como uma extensão das capacidades humanas. Não deve ser encarado como uma ferramenta pois possui capacidades cognitivas inexistentes em equipamentos mecânicos tradicionais. É uma extensão da mente e não da força. Ele altera as noções préestabelecidas de sensações o que causa uma reinterpretação do ambiente em que nos colocamos. As interações podem extrapolar o âmbito da percepção mental à interação física, através da realidade aumentada (PICON in SYKES, 2013). O comportamento espacial humano se remodela em função do teclado, mouse, joystick e tela sensível ao toque.
}

criação no momento em que o processamento de um algoritmo adquiri a capacidade de criar (TERZIDIS, 2006).

\section{Considerações Finais}

A concepção de projeto assistida por computador não demonstra apenas uma adequação do designer ao meio digital - no sentido de se adaptar às dinâmicas estabelecidas no tempo que identificados como Era Digital (OXMAN, 2006) -, ela também instiga a capacidade de simulação e teste de modelos virtuais. Análises da ação de catástrofes ambientais, aumento de população e simulações de uso e ocupação em processos participativos, logo nas primeiras etapas de projeto, podem culminar em um resultado construtivo capaz de resistir a tais interferências externas (KOLAREVIC, 2004). Respostas complexas como síntese da análise de problemas complexos identificados pela humanidade (VASSÃO, 2010).

O pensamento humano aparenta ser livre e infinito, mas suas limitações estão ligadas ao poder de compreensão de cada indivíduo, e seu discernimento é pautado em suas experiências e vivências. Em outras palavras, o discernimento humano segue regras sociais, naturais e holísticas, barreiras criadas pelo intelecto humano para cercar o que é conhecido do que não é, do inimaginável, do incrível e mágico inesperado (TERZIDIS, 2006). Muitas decisões de projeto baseadas na chamada intuição, podem se apresentar arbitrárias e obscuras (NATIVIDADE, 2010). O computador "[...] rompe com o imediatismo do gesto humano [...]" (PICON, 2004, pág. 209).

Fazer uso da informatização no processo de projeto pode significar estar refém de um software comercial. O designer assume uma posição de distanciamento em relação ao uso de sua ferramenta. Tratamos aqui de assumir o controle de suas próprias ferramentas, e se possível, desenvolve-las sozinho (NATIVIDADE, 2012).

Ao contrário das ferramentas tradicionais de desenho, com as quais o arquiteto estabelece uma relação física, na computação, o arquiteto deve estabelecer uma relação intelectual com o algoritmo por conta de sua natureza abstrata. Ficar reféns de um software significa perder o controle do potencial criativo, já que agora são os programas que limitam nossos pensamentos. Dominar a constituição primária do software (algoritmos) significa uma emancipação

${ }^{7}$ A vida artificial (AL - artificial life) se refere a capacidade de máquinas obterem características naturais extremamente complexas - um sistema que se mantém "true to natural life" ((LANGTON apud WHITELAW in HENNO, 2016). A AL está apoiada em conceitos da genética e emergência, que se refere ao "processo pelo qual os simples componentes de um nível inferior interagem produzindo resultados complexos e sofisticados, próximos ao que encontramos na matéria viva. " (HENNO, 2016). Já a inteligência artificial (Al artificial intelligence) é limitada a reproduções pré-programadas de respostas a estímulos orientados, onde o sistema deve apresentar uma organização baseada em regras locais previamente definidas. Ao contrário da vida artificial, possui baixo grau de autonomia, no momento em que "(...) não possui (...) relação com o método pelo qual a inteligência é formada nos sistemas naturais. "(HENNO, 2016). ${ }^{8}$ Algoritmos que tem como código fonte sua simples multiplicação, ou, em casos de algoritmos com maior autonomia, escrever outros algoritmos com pequenas modificações (mutações). 
digital em um mundo que se tornou "[...] codificado pela imaginação tecnológica." (FLUSSER, 2007, pág. 137).

E no mais, não se trata apenas de estar no controle de sua própria criação do ponto de vista de ferramenta (AISH apud BURRY, 2011), mas de abrir mão da própria autoria. Aceitar a inserção de um agente externo não humano dentro de seu processo de projeto.

As tecnologias digitais definem a arquitetura contemporânea em um momento de incertezas e diversas opções de caminhos a serem tomados dentro da disciplina. Entender o real potencial da aplicação de máquinas de processamento dentro do processo de criação pode elucidar o futuro da produção nesse campo.

As dificuldades presentes no desenvolvimento dos experimentos apresentados mostram a defasagem na disseminação de conhecimentos sobre lógica e programação dentro dos ambientes de ensino da arquitetura, urbanismo e design.

A profundidade teórica e prática possível de ser alcançada pelo tema abordado sugere uma continuidade das experimentações. Um caminho possível, por exemplo, são estudos cruzados entre psicologia e filosofia - a necessidade de compreender os processos cognitivos humanos é uma realidade no momento em que se deseja entender qual o posicionamento de cada agente em um processo de projeto compartilhado. Além disso, se faz primordial entender as relações que se estabelecem entre sujeito e objeto (MATURANA, 2014) em um mundo gerido pela introdução do espaço virtual (CARDOSO, 2016).

\section{Agradecimentos}

Agradecemos ao Comitê de Organização do XXI Congresso da Sociedade Ibero-americana de Gráfica Digital pela oportunidade concedida em apresentar este trabalho; ao Grupo de Pesquisa Teoria e Projeto na Era Digita (TPED); à Faculdade de Arquitetura e Urbanismo da Universidade Presbiteriana Mackenzie (FAUUPM); e aos colegas professores e alunos.

\section{Referências}

Burry, M. (2011). Scripting cultures: Architectural design and programming. West Sussex, Reino Unido: John Wiley \& Sons.

Cardoso, R. (2016). Design para um mundo complexo. São Paulo, SP: Ubu Editora LTDA-ME;

Calixto, V., \& Celani, G. (2015). A literature review for space planning optimization using an evolutionary algorithm approach: 19922014. XIX SiGraDi. São Paulo, SP: Blucher;

Coates, P. (2010). Programming Architecture. Nova York, EUA: Routledge;
Chu, K. S. A metafísica da arquitetura genética e da computação, 2006. In. Sykes, A. Krista (org.). O campo ampliado da arquitetura: antologia teórica 1993-2009. São Paulo: Cosac Naify, 2013;

Flusser, V., \& Cardoso, R. (2007). O mundo codificado: por uma filosofia do design e da comunicação. São Paulo, SP: Editora Cosac Naify;

Henno, J. H. (2016). As correlações entre os sistemas generativos e a fabricação digital no contexto das artes visuais. Escola de Comunicações e Artes / USP. Orientadora: Monica Baptista Sampaio Tavares. São Paulo, SP;

Kolarevic, B. (Ed.). (2004). Architecture in the digital age: design and manufacturing. Taylor \& Francis;

Luce, K. M. (2009). Revolutions in parallel: The rise and fall of drawing in architectural design. Tese (Doutorado). University of Michigan. Ann Arbor;

Maturana, H. (2014). Cognição, ciência e vida cotidiana. Organização e tradução Cristiana Magro, Victor Paredes. 2 ed. - Belo Horizonte: Editora UFMG;

Natividade, V. G. (2010). Fraturas metodológicas nas arquiteturas digitais. Dissertação (Mestrado em Arquitetura e Urbanismo Projeto de Arquitetura). Universidade de São Paulo. São Paulo;

Natividade, V. G. (2012) Para além dos clichés paramétricos. PUCRio - SiGraDi;

Oxman, R. (2006). Theory and design in the first digital age. Design Studies, 27(3), 229-265.

Picon, A. A arquitetura e o virtual: Rumo a uma nova materialidade, 2004. In. Sykes, A. Krista (org.). O campo ampliado da arquitetura: antologia teórica 1993-2009. São Paulo: Cosac Naify, 2013;

Terzidis, K. (2006). Algorithmic architecture. Nova York, EUA: Routledge;

Vassão, C. A. (2010). Metadesign: ferramentas, estratégias e ética para a complexidade. São Paulo: Blucher; 